\title{
MicroRNA-21-5p acts via the PTEN/Akt/FOXO3a signaling pathway to prevent cardiomyocyte injury caused by high glucose/high fat conditions
}

\author{
YING HAN $^{1,2}$, XIAOQI CAI ${ }^{1,2}$, MIN PAN $^{1,2}$, JIN GONG $^{1,2}$, \\ WENQIN CAI ${ }^{1,2}$, DAN LU ${ }^{3}$ and CHANGSHENG XU ${ }^{2}$ \\ ${ }^{1}$ Department of Geriatrics; ${ }^{2}$ Fujian Institute of Hypertension; ${ }^{3}$ Department of General Medicine, \\ The First Affiliated Hospital of Fujian Medical University, Fuzhou, Fujian 350005, P.R. China
}

Received November 11, 2020; Accepted Septembe 15, 2021

DOI: $10.3892 / \mathrm{etm} .2022 .11154$

\begin{abstract}
MicroRNAs (miRNAs or miRs) play important roles in cardiovascular disease. miR-21-5p is known to be involved in the regulation of cardiomyocyte injury under high glucose and high fat (HG-HF) conditions, but its mechanism of action remains unclear. In the present study, a cardiomyocyte cell line, $\mathrm{H} 9 \mathrm{c} 2$, was treated with $33 \mathrm{mM}$ glucose and $250 \mu \mathrm{M}$ sodium palmitate for 24,48 , and $72 \mathrm{~h}$ to produce HG-HF injury. After treatment, miR-21-5p expression was detected by reverse transcription-quantitative PCR. A miR-21-5p mimic was then constructed and transfected into the cells and the potential molecular mechanism was investigated using Cell Counting Kit-8, TUNEL, flow cytometry and western blot assays. Expression of miR-21-5p was significantly downregulated by HG-HF treatment of $\mathrm{H} 9 \mathrm{c} 2$ cells for 24,48 , and $72 \mathrm{~h}$. In subsequent experiments, cells were treated for an intermediate period (48 h). Compared with the control group, HG-HF treatment significantly inhibited $\mathrm{H} 9 \mathrm{c} 2$ proliferation and promoted apoptosis, while these effects were significantly reduced in the miR-21-5p mimic. Compared with the control group, HG-HF treatment significantly increased reactive oxygen species, while miR-21-5p mimic significantly reduced this effect. Compared with the control group, HG-HF treatment significantly increased the expression of the pro-apoptotic proteins Bax and phosphorylated (p)-Akt and decreased the expression of the anti-apoptotic proteins Bcl-2, p-PTEN, and p-FOXO3a, while overexpression of miR-21-5p significantly reduced these effects. The results revealed that miR-21-5p inhibited apoptosis
\end{abstract}

Correspondence to: Dr Ying Han, Department of Geriatrics, The First Affiliated Hospital of Fujian Medical University, 20 Chazhong Road, Fuzhou, Fujian 350005, P.R. China

E-mail: hyhanying@aliyun.com

Key words: rat H9c2 cells, microRNA-21-5p, high glucose and high fat, apoptosis, oxidative stress, PTEN/Akt/FOXO3a signaling pathway and oxidative stress in $\mathrm{H} 9 \mathrm{c} 2$ cells induced by HG-HF, likely through the PTEN/Akt/FOXO3a signaling pathway.

\section{Introduction}

Epidemiological studies have indicated that the incidence of diabetes mellitus (DM) is increasing annually worldwide, while diabetic cardiomyopathy (DCM) is the main factor contributing to heart failure in diabetic patients without coronary heart disease or hypertension $(1,2)$. However, the pathogenesis of DCM is very complex and not yet fully understood. Long-term hyperglycemia can act on the respiratory chain, increase production of reactive oxygen species (ROS) and oxidative stress, and further induce myocardial apoptosis $(3,4)$. Due to the non-renewable characteristics of myocardial cells, cardiac function gradually declines with cardiomyocyte apoptosis.

MicroRNAs (miRNAs or miRs) are non-coding small molecule RNAs regulating post-transcriptional gene expression. They can inhibit mRNA translation or target mRNA degradation by binding to specific mRNAs, thus regulating gene expression (5). MiRNAs play important roles in cardiovascular disease. For example, miR-17-5p and miR-1594 are important regulators of cellular responses to heart injury $(6,7)$. miR-21-5p is involved in numerous diseases, including lung and endometrial fibrosis $(8,9)$, but its exact function in heart disease remains controversial. Qiao et al reported that miR-21-5p can enhance angiogenesis and myocardial cell survival by regulating the phosphatase and tensin homolog (PTEN)-Akt signaling pathway, thus contributing to cardiac repair (10). Expression of miR-21-5p is affected by isoflurane preconditioning in a rat model of myocardial infarction (11). However, the mechanism by which miR-21-5p regulates cardiomyocyte injury under high glucose and high fat (HG-HF) conditions is unclear.

In the present study, a miR-21-5p mimic was constructed to study its effect on apoptosis in cardiomyocytes under HG-HF conditions and to provide improved understanding of its mechanism of action. The results of the present study have important implications for the pathogenesis of DCM and for research on possible treatments. 


\section{Materials and methods}

Cell culture and treatments. $\mathrm{H} 9 \mathrm{c} 2$ cells were purchased from American Type Culture Collection (ATCC) and cultured in Dulbecco's modified Eagle's medium (DMEM) supplemented with $10 \%$ fetal bovine serum (FBS; Hyclone; GE Healthcare Life Sciences). The cells were passaged when their density reached $80-90 \%$. The supernatant was then discarded and the cells were washed twice with $1 \mathrm{X}$ PBS. The cells were then treated with $0.25 \%$ trypsin (containing $0.02 \%$ EDTA; 3 min at $37^{\circ} \mathrm{C}$ ) to detach them from the culture vessel. Subsequently, the cells became round, and complete medium was added to terminate the digestion. The cells were centrifuged at $875 \mathrm{xg}$ for $3 \mathrm{~min}$ at room temperature. The cell suspension was divided into new culture dishes at a ratio of 1:3, marked and placed in a $5 \% \mathrm{CO}_{2}$ incubator at $37^{\circ} \mathrm{C}$. $\mathrm{H} 9 \mathrm{c} 2$ cells were cultured in DMEM containing $33 \mathrm{mM}$ glucose (HG) and $250 \mu \mathrm{M}$ sodium palmitate (HF) for 24, 48 and $72 \mathrm{~h}$ to induce HG-HF injury as previously described (12). DMEM supplemented with $5.5 \mathrm{mM}$ glucose was used as a control.

Transfection. A total of two sterilized Eppendorf tubes were prepared for each group of cells. Each tube was filled with $62.5 \mu \mathrm{l}$ Opti-MEM ${ }^{\mathrm{TM}}$ (Thermo Fisher Scientific, Inc.). In addition, one tube was filled with $2.5 \mu$ l Lipofectamine ${ }^{\circledR} 3000$ (Thermo Fisher Scientific, Inc.) while the other with $6.25 \mu \mathrm{l}$ of either a negative control (NC) mimic (5'-UCACAA CCUCCUAGAAAGAGUAGAUCUACUCUUUCUAGGA GGUUGUGA-3') or a miR-21-5p mimic (5'-UAGCUUAUC AGACUGAUGUUGAUCA ACAUCAGUCUGAUAAG CUA-3') from General Biosystems (Anhui) Co., Ltd., and both were then incubated at room temperature for $5 \mathrm{~min}$. The two tubes were evenly mixed and incubated at room temperature for $15 \mathrm{~min}$, after which the mixed solution was dropped into wells in a 6-well plate before the cells were returned to the incubator. Following $48 \mathrm{~h}$ of transfection of the H9c2 cells, transfection efficiency was detected by reverse transcription-quantitative PCR (RT-qPCR) and the treatment groups were cultured in HG-HF medium for an additional $48 \mathrm{~h}$ at $37^{\circ} \mathrm{C}$.

TUNEL assay. Cells $\left(3 \times 10^{5}\right.$ cells $\left./ \mathrm{ml}\right)$ were fixed with $4 \%$ paraformaldehyde for $15 \mathrm{~min}$ at room temperature, washed 3 times with PBS, and then permeated for $20 \mathrm{~min}$ at room temperature in PBS containing 0.5\% Triton X-100. PBS was used to wash the culture dishes 3 times ( 3 min each). TUNEL solution was added to each well and incubated for $1.5 \mathrm{~h}$ at $45^{\circ} \mathrm{C}$. DAPI $(5 \mu \mathrm{g} / \mathrm{ml})$ was added to stain the nuclei for $5 \mathrm{~min}$ at room temperature. The culture dish was sealed with $50 \%$ glycerol, and images from at least five fields in each section were taken under a fluorescence microscope (magnification, x200).

Measurement of ROS. To assess the levels of ROS, the cells $\left(3 \times 10^{5}\right.$ cells $\left./ \mathrm{ml}\right)$ were incubated with DCFH-DA $(10 \mu \mathrm{M})$ (Beyotime Institute of Biotechnology) at $37^{\circ} \mathrm{C}$ for $20 \mathrm{~min}$. Subsequently, they were washed three times with serum-free medium to remove excess DCFH-DA. ROS levels were then analyzed by flow cytometry (FACSCalibur; BD Biosciences). The data were analyzed by FlowJo 7.6 (FlowJo LLC).
Measurement of nitric oxide (NO) level. The levels of NO were measured in the cells $\left(3 \times 10^{5}\right.$ cells $\left./ \mathrm{ml}\right)$ using the double antibody sandwich method according to the manufacturer's instructions (cat. no. MM-20607R1; Jiangsu Enzyme Industry Co., Ltd.).

$R T-q P C R$. Total RNA was extracted from cells using an Ultrapure RNA extraction kit according to the manufacturer's instructions (CoWin Biosciences). The concentration and purity of RNA $\left(\mathrm{OD}_{260} / \mathrm{OD}_{280}\right)$ were determined by a UV-Vis spectrophotometer. RNA was reversely transcribed into cDNA using a miRNA cDNA Synthesis Kit according to the manufacturer's instructions (cat. no. CW2141S; CoWin Biosciences). The reaction system for qPCR was as follows: RNase free $\mathrm{dH}_{2} \mathrm{O}, 9.5 \mu \mathrm{l}$; cDNA, $1 \mu \mathrm{l}$; upstream primer, $1 \mu \mathrm{l}$; downstream primer, $1 \mu \mathrm{l}$; and 2X SYBR Green PCR Master Mix (miRNA qPCR Assay Kit; cat. no. CW2142S; CoWin Biosciences), $12.5 \mu 1$. The reaction steps were as follows: Pre-denaturation at $95^{\circ} \mathrm{C}$ for $10 \mathrm{~min}$; denaturation at $95^{\circ} \mathrm{C}$ for $10 \mathrm{sec}$; annealing at $58^{\circ} \mathrm{C}$ for $30 \mathrm{sec}$; and extension at $72^{\circ} \mathrm{C}$ for $30 \mathrm{sec}$, carried out over 40 cycles. The primers were designed based on poly(A) tailing reaction method (13) and synthesized by General Biosystems (Anhui) Co., Ltd., using the following sequences: miR-21-5p forward, 5'-TAGCTTATCAGACTGATGTTGA-poly(A)-3' and the reverse primer (5'-AGTGCAGGGTCCGAGGTATT-3') was a general primer in the kit (2X SYBR Green PCR Master Mix; CoWin Biosciences); U6 forward, 5'-GCTTCGGCAGCACATT ACTACTATAAAAT-3' and reverse, 5'-CGCTTCACGGAATT TGCGTGTCAT-3'. The target gene expression was calculated using the $2^{-\Delta \Delta \mathrm{Cq}}$ method (14).

Western blotting. Cells were collected and total protein was extracted using TriplePrep kit according to the manufacturer's instructions (cat. no. 28-9425-44; ReadyPrep; Cytiva). After $30 \mathrm{~min}$ on ice, the lysate was centrifuged at $8798 \mathrm{x}$ g for $10 \mathrm{~min}$ at $4^{\circ} \mathrm{C}$. Protein concentration was determined using a BCA kit (Beyotime Institute of Biotechnology). A total of $(20 \mu \mathrm{g})$ per protein sample was denatured, and the samples were separated by $12 \%$ SDS-PAGE for $2 \mathrm{~h}$, followed by transfer to a PVDF membrane. Following blocking in 5\% skim milk for $2 \mathrm{~h}$ at room temperature, the membranes were incubated with primary antibodies at $4^{\circ} \mathrm{C}$ overnight, and then the membranes were incubated with a secondary antibody at room temperature for $2 \mathrm{~h}$. The primary antibodies included mouse monoclonal anti-GAPDH (1:2,000; cat. no. TA-08; ZSGB-BIO), rabbit anti-phosphorylated (p)-PTEN (1:1,000; cat. no. AF3351; Affinity Biosciences), rabbit anti-p-AKT (1:1,000; cat. no. AF0016; Affinity Biosciences) rabbit anti-p-FOXO3a (1:1,000; cat. no. AF3020; Affinity Biosciences), rabbit anti-Bax (1:1,000; cat. no. A0207; ABclonal Biotech Co., Ltd.), and mouse anti-Bcl-2 (1:500; product code ab692; Abcam). The secondary antibodies $(1: 10,000)$ were HRP-labeled goat anti-rabbit IgG (cat. no. 65-6120; Thermo Fisher Scientific, Inc.) and HRP-labeled goat anti-mouse IgG (cat. no. 31430; Thermo Fisher Scientific, Inc.). Enhanced chemiluminescence exposure solution (cat. no. CW0049; CoWin Biosciences) was added to the membrane and exposed in a gel imaging system. The gray value was analyzed by Quantity One software (version 4.62; Bio-Rad Laboratories, Inc.). 

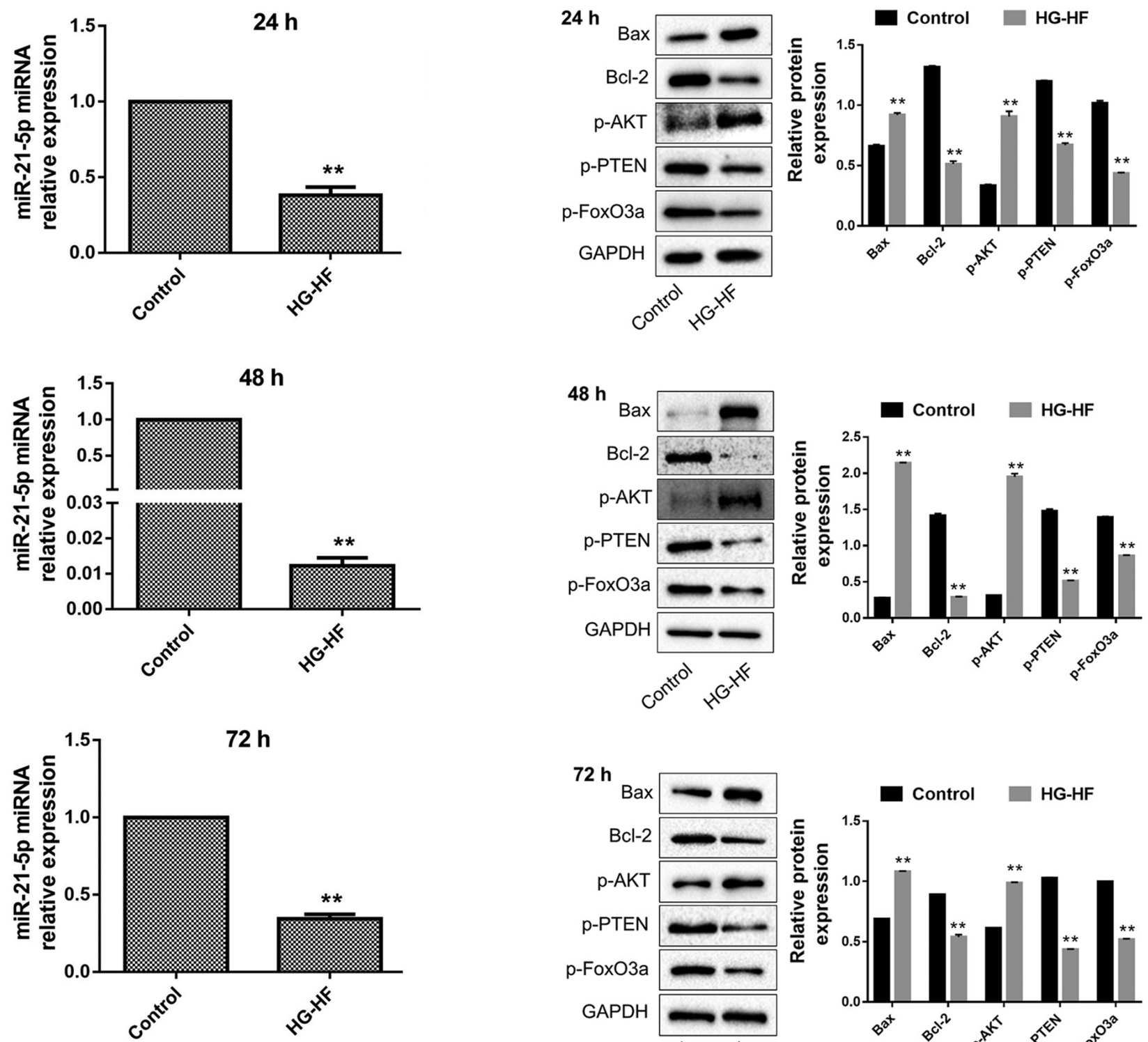

Figure 1. Effects of high levels of glucose and fat on the expression of microRNA-21-5p in $\mathrm{H} 9 \mathrm{c} 2$ cells. ${ }^{* *} \mathrm{P}<0.01$ compared with the control group ( $\mathrm{n}=6$ in each group). HG-HF, high glucose-high fat; miR, microRNA.

Statistical analysis. All data are expressed as the mean \pm standard deviation (SD; $\mathrm{n}=6$ in each group) and analyzed by Graphpad Prism version 7 (GraphPad Software, Inc.). Results from the two groups were compared using unpaired Student's t-test and one-way ANOVA followed by Bonferroni's correction were applied to compare three or more groups. $\mathrm{P}<0.05$ was considered to indicate a statistically significant difference.

\section{Results}

HG-HF downregulates the expression of miR-21-5p in $H 9 c 2$ cells. To explore the effect of HG-HF on the expression of miR-21-5p in H9c2 cells, RT-qPCR was used to detect the expression of miR-21-5p mRNA. The results are revealed in Fig. 1. Compared with the control group, the expression of miR-21-5p in H9c2 cells was significantly reduced by treatment with HG-HF for 24, 48, and $72 \mathrm{~h}$.
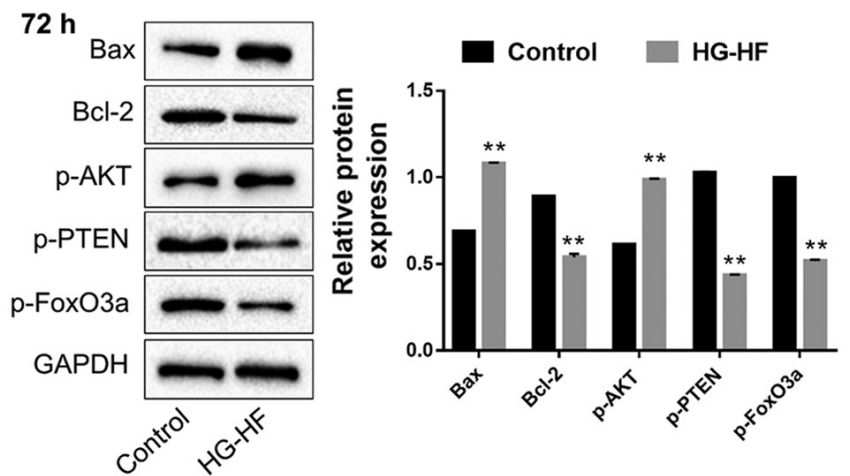

Figure 2. Effects of high levels of glucose and fat on expression of apoptosis-related and PTEN/Akt/FOXO3a proteins in $\mathrm{H} 9 \mathrm{c} 2$ cells. ${ }^{* * *} \mathrm{P}<0.01$ compared with the control group ( $\mathrm{n}=6$ in each group). HG-HF, high glucose-high fat; p-, phosphorylated.

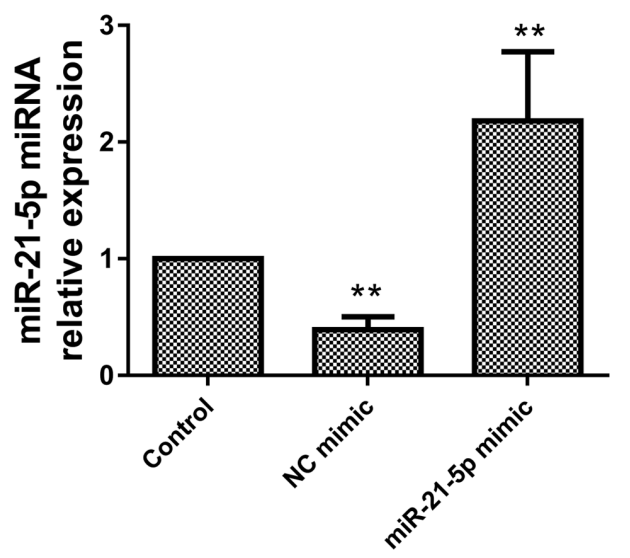

Figure 3. miR-21-5p mimic promotes miR-21-5p expression in $\mathrm{H} 9 \mathrm{c} 2$ cells. ${ }^{* *} \mathrm{P}<0.01$ compared with the control group ( $\mathrm{n}=6$ in each group). miR, microRNA. 

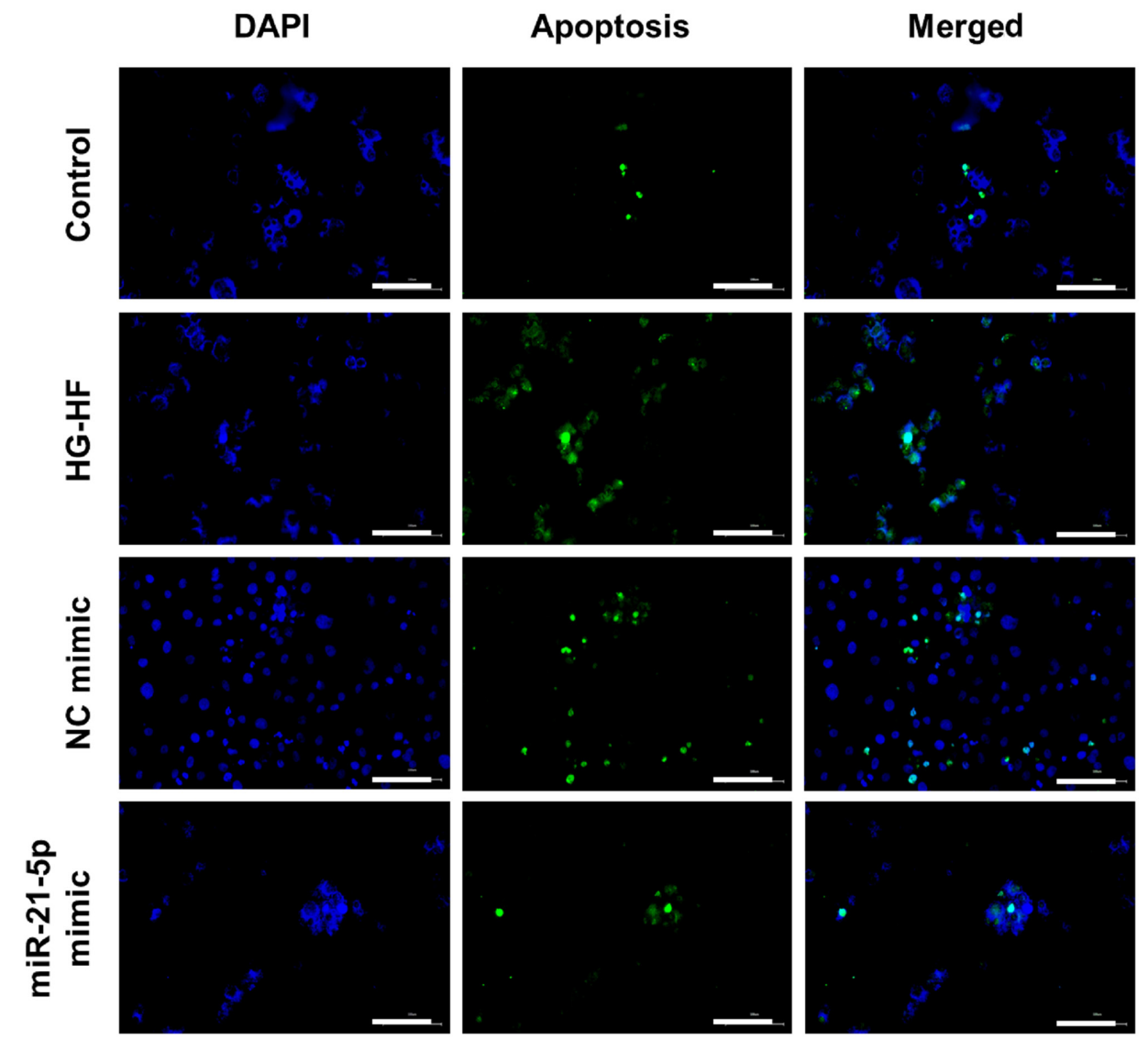

Figure 4. MicroRNA-21-5p mimic reduces apoptosis in H9c2 cells caused by high glucose and high fat treatment. HG-HF, high glucose-high fat; miR, microRNA.

$H G-H F$ triggers apoptosis-related protein expression and modulates PTEN/Akt/FOXO3a signaling. The expression levels of the apoptosis-related proteins Bax/Bcl-2 and PTEN/Akt/FOXO3a were detected by western blotting. Compared with the control group, HG-HF treatment for 24,48 , and $72 \mathrm{~h}$ significantly increased the expression of the pro-apoptotic proteins Bax and p-Akt, while it significantly decreased the expression of the anti-apoptotic proteins Bcl-2, p-PTEN and p-FOXO3a (Fig. 2).

miR-21-5p mimic promotes miR-21-5p expression in $H 9 c 2$ cells. To verify transfection of miR-21-5p in H9c2 cells, the expression of miR-21-5p was assessed using RT-qPCR. Compared with the control group, the miR-21-5p mimic significantly increased the expression of miR-21-5p (Fig. 3), indicating that miR-21-5p was overexpressed in the H9c2 cells.

miR-21-5p mimic reduces apoptosis of H9c2 cells caused by $H G-H F$. TUNEL staining was used to detect apoptosis, and the results were revealed in Fig. 4. Compared with the control H9c2 cells, HG-HF treatment significantly promoted apoptosis while the miR-21-5p mimic inhibited apoptosis induced by HG-HF (Fig. 4).

Effects of the miR-21-5p mimic on NO levels and oxidative stress in H9c2 cells. In order to explore the effect of miR-21-5p mimic on oxidative stress in H9c2 cells, flow cytometry was used to detect ROS. Compared with the control group, HG-HF treatment significantly increased the level of ROS, while the miR-21-5p mimic significantly decreased ROS levels in the HG-HF group (Fig. 5A and B). Conversely, the miR-21-5p mimic had no significant effect on NO levels in H9c2 cells (Fig. 5C).

miR-21-5p mimic inhibits apoptosis induced by HG-HF in H9c2 cells, likely via the PTEN/Akt/FOXO3a signaling pathway. To further explore the effect of miR-21-5p on apoptosis of $\mathrm{H} 9 \mathrm{c} 2$ cells induced by HG-HF and to identify its molecular mechanism, the expression levels of the apoptosis-related proteins $\mathrm{Bax} / \mathrm{Bcl}-2$ and the signaling pathway proteins PTEN/Akt/FOXO3a were detected by western blotting. Compared with the control group, HG-HF treatment significantly increased the expression of the pro-apoptotic proteins Bax and p-Akt and decreased the expression of the anti-apoptotic proteins Bcl-2, p-PTEN and p-FOXO3a, but these effects were greatly reduced in the miR-21-5p mimic group (Fig. 6). These data indicated that the miR-21-5p mimic inhibited $\mathrm{H} 9 \mathrm{c} 2$ cell apoptosis induced by HG-HF, likely via the PTEN/Akt/FOXO3a signaling pathway.

\section{Discussion}

The steady increase in the number and mortality of diabetic patients is partly due to DM-related heart disease (15), including abnormal cardiac structure and function such as left ventricular dysfunction, myocardial apoptosis, and myocardial fibrosis (16). Cardiomyocyte apoptosis has been considered a 
A

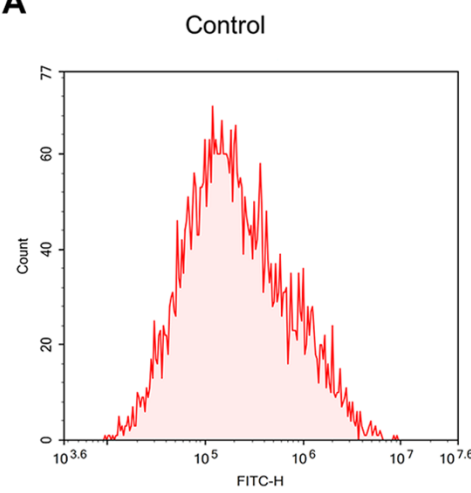

NC mimic

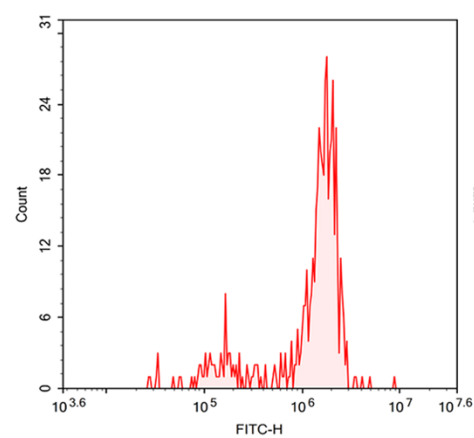

HG-HF

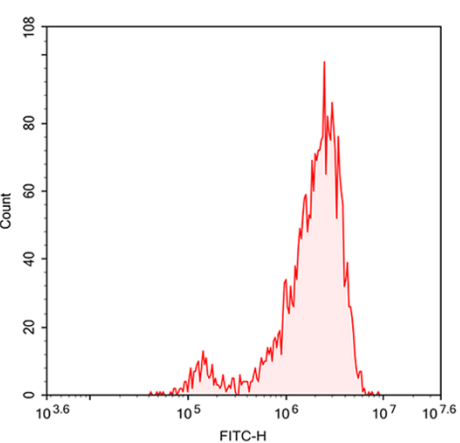

miR-21-5p mimic

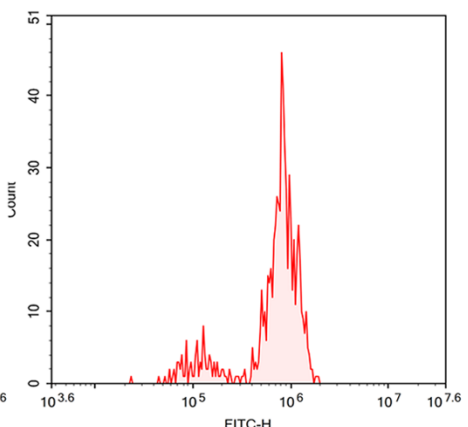

B

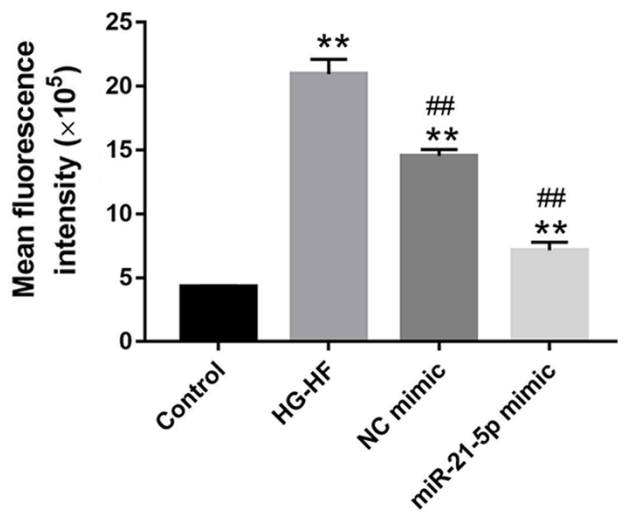

C

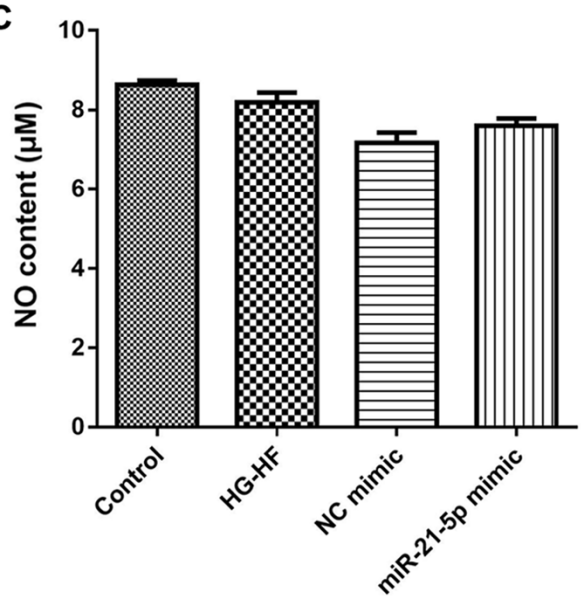

Figure 5. Effects of microRNA-21-5p mimic on oxidative stress in H9c2 cells. (A) Representative images and (B) quantification of the levels of reactive oxygen species in $\mathrm{H} 9 \mathrm{c} 2$ cells detected by flow cytometry. (C) Nitric oxide content in H9c2 cells. ${ }^{* *} \mathrm{P}<0.01$ compared with the control group; ${ }^{\# \#} \mathrm{P}<0.01$ compared with the HG-HF group ( $\mathrm{n}=6$ in each group). HG-HF, high glucose-high fat; NC, negative control; miR, microRNA; NO, nitric oxide.
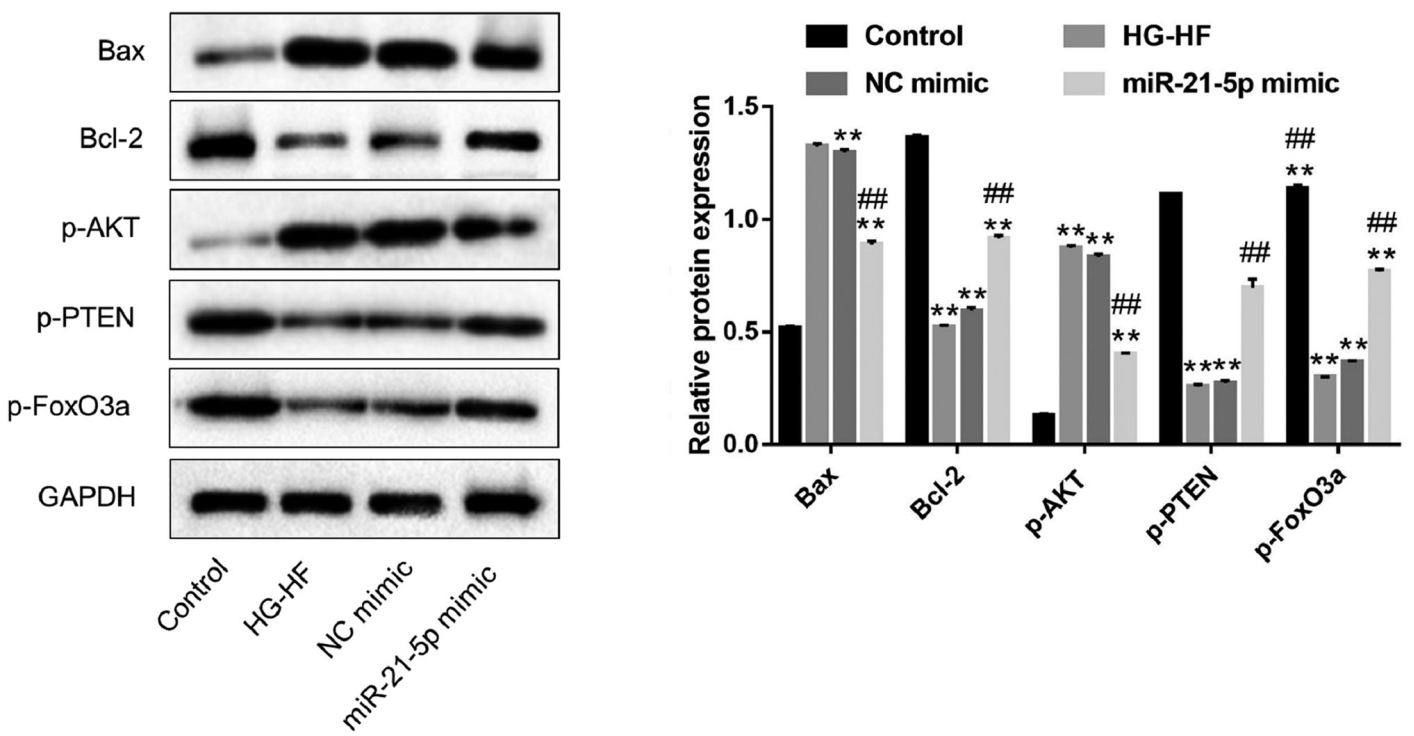

Figure 6. Effects of microRNA-21-5p mimic on apoptosis in H9c2 cells and the expression of PTEN/Akt/FOXO3a signaling proteins. ** $\mathrm{P}<0.01$ compared with the control group; ${ }^{\#} \mathrm{P}<0.01$ compared with the HG-HF group ( $\mathrm{n}=6$ in each group). HG-HF, high glucose-high fat; miR, microRNA; p-, phosphorylated; NC, negative control.

potential mechanism for the development of cardiomyopathy and heart failure $(17,18)$.

It has been observed that the PTEN/Akt signaling pathway is important for regulation of cell apoptosis, inflammation, and synaptic plasticity $(19,20)$. PTEN was initially recognized as a tumor suppressor that can antagonize the effect of PI3K and downregulate PIP3 (21-23). PIP3 can increase the level of p-Akt and participate in the growth and survival of cells. 
PTEN is a negative regulator of the PI3K/Akt pathway and plays an important role in regulation of cell growth, differentiation, apoptosis, migration, and neuronal plasticity $(19,20)$. The FOXO protein is a member of the forkhead transcription factor family. Its common characteristic is the forkhead protein (Fox) domain, which plays an important role in apoptosis via regulation of the PI3K/Akt pathway. Li et al (24) found that the PTEN/Akt/FOXO3a pathway plays an important role in hypoxia and ischemia-induced neuronal apoptosis in rats. In the present study, it was revealed that p-Akt was significantly upregulated and p-PTEN and p FOXO3a were significantly downregulated. Additionally, upregulation of the pro-apoptotic protein Bax and downregulation of the anti-apoptotic protein Bcl-2 were observed after 24, 48, and $72 \mathrm{~h}$ of HG-HF treatment, which indicated that HG-HF promoted H9c2 cell apoptosis through the PTEN/Akt/ FOXO3a signaling pathway.

miR-21 (miRBase Accession number: MI0000077) is a stem-loop precursor sequence and is processed into two mature miRNA sequences, miR-21-5p (miRBase Accession number: MIMAT0000076) and miR-21-3p (miRBase Accession number: MIMAT0004494). miR-21-5p and miR-21-3p are derived from $5^{\prime}$ and $3^{\prime}$ ends of miR-21, respectively (25). MiR-21 is differentially expressed in numerous cardiovascular diseases, including neointimal injury, myocardial infarction, heart failure, as well as other pathological states, and in cardiomyocyte apoptosis associated with a variety of conditions (10). Sayed et al (26) revealed that miR-21 was sensitive to sustained hypoxia, which could downregulate the expression of miR-21 in cardiomyocytes. Cheng et al (27) identified that miR-21 was sensitive to hydrogen peroxide, which could upregulate the expression of miR-21 in cardiomyocytes. Regulation of PTEN by miR-21 has been reported in cancer and cardiovascular injury $(28,29)$. Interestingly, miR-21-5p has also been revealed to perform key roles in heart diseases. Knockdown of miR-21-5p decreases myocardial infarction injury, indicating that miR-21-5p may play an active role in post-myocardial infarction repair $(30,31)$. In the present study, it was revealed that the expression of miR-21-5p in HG-HF-induced cardiomyocytes was significantly lower than in a normal control group. miR-21-5p mimic inhibited Bax expression and increased $\mathrm{Bcl}-2$ expression to inhibit cell apoptosis, and also reduced the effect of HG-HF on the PTEN/Akt/FOXO3a signaling pathway, indicating that miR-21-5p regulates the PTEN/Akt/FOXO3a signaling pathway to inhibit HG-HF-induced apoptosis in cardiomyocytes. Although the specific function of miR-21 and miR-21-5p in heart diseases was not distinguished, the mimic of miR-21 may also exert a similar function, since miR-21-5p is a mature product of miR-21. In addition, the function of miR-21-3p should also be investigated in future.

Oxidative stress is widely reported in numerous pathophysiological processes, such as aging, inflammation, and psychiatric disorders (32). Studies have revealed that autophagy and apoptosis are ROS-dependent (33), and ROS are involved in regulation of apoptosis (34). In the present study, ROS levels in the experimental groups were also detected using flow cytometry. HG-HF treatment increased ROS in H9c2 cells, while the miR-21-5p mimic decreased ROS in the HG-HF group. These data may suggest that the
miR-21-5p mimic inhibits HG-HF-induced apoptosis of cardiomyocytes by regulating ROS. NO generated within the heart has long been known to influence vascular homoeostasis (35), but it was revealed that the miR-21-5p mimic had no significant effect on NO levels in the H9c2 cells. These data indicated that regulation of apoptosis by miR-21-5p is independent of NO.

There are a few limitations in the present study. Firstly, whether miR-21-5p has other anti-apoptotic mechanisms and whether the PTEN/Akt/FOXO3a pathway is the downstream target of miR-21-5p in cardiomyocyte apoptosis induced by HG-HF remains unclear. Therefore, the relationship between miR-21-5p and PTEN/Akt/FOXO3a signaling in inhibiting apoptosis in cardiomyocytes needs further study. Secondly, our research was limited to in vitro cell experiments; animal experiments and human clinical trials have not yet been carried out. The present study provided a preliminary conceptual and experimental basis for the use of miR-21-5p in the treatment of diabetic cardiomyopathy.

In conclusion, our results indicated that miR-21-5p inhibits apoptosis in cardiomyocytes induced by HG-HF, and may act via the PTEN/Akt/FOXO3a signaling pathway.

\section{Acknowledgements}

Not applicable.

\section{Funding}

The present study was supported by the Natural Science Foundation of Fujian (grant no. 2018J01166), the Medical Innovation Project of Fujian Health Commission (grant no. 2019-cx-29) and the Promotion Project of Fujian Health and Family Planning Commission for Rural Urban Communities (grant no. 2018017).

\section{Availability of data and materials}

The datasets used and/or analyzed during the current study are available from the corresponding author on reasonable request.

\section{Authors' contributions}

$\mathrm{YH}, \mathrm{XC}, \mathrm{MP}, \mathrm{JG}, \mathrm{WC}$, DL and CX performed the experiments and analyzed the data. YH designed the study and wrote the manuscript. All authors have read and approved the final manuscript. YH, XC, MP, JG, WC, DL and CX confirmed the authenticity of the raw data.

\section{Ethics approval and consent to participate}

Not applicable.

\section{Patient consent for publication}

Not applicable.

\section{Competing interests}

The authors declare that they have no competing interests. 


\section{References}

1. Picano E: Diabetic cardiomyopathy. the importance of being earliest. J Am Coll Cardi-ol 42: 454-457, 2003.

2. Avogaro A, Vigili de Kreutzenberg S, Negut C, Tiengo A and Scognamiglio R: Diabetic cardiomyopathy: A metabolic perspective. Am J Cardiol 93: 13A-16A, 2004.

3. Zhang BB, Zhou G and Li C: AMPK: An emerging drug target for diabetes and the metabolic syndrome. Cell Metab 9: 407-416, 2009

4. Li B, Zheng Z, Wei Y, Wang M, Peng J, Kang T, Huang X, Xiao J, Li Y and Li Z: Therapeutic effects of neuregulin-1 in diabetic cardiomyopathy rats. Cardiovasc Diabetol 10: 69, 2011.

5. Wang Y, Zou L, Wu T, Xiong L, Zhang T, Kong L, Xue Y and Tang M: Identification of mRNA-miRNA crosstalk in human endothelial cells after exposure of PM2.5 through integrative transcriptome analysis. Ecotoxicol Environ Saf 169: 863-873, 2019.

6. Yang J, Shi G, Gong Y, Cai J, Zheng Y and Zhang Z: LncRNA 0003250 accelerates heart autophagy and binds to miR-17-5p as a competitive endogenous RNA in chicken induced by selenium deficiency. J Cell Physiol 236: 157-177, 2021.

7. Yang J, Gong Y, Cai J, Liu Q and Zhang Z: lnc-3215 Suppression Leads to Calcium Overload in Selenium Deficiency-Induced Chicken Heart Lesion via the lnc-3215-miR-1594-TNN2 Pathway. Mol Ther Nucleic Acids 18: 1-15, 2019.

8. Song M, Zhao G, Sun H, Yao S, Zhou Z, Jiang P, Wu Q, Zhu H, Wang H, Dai C, et al: circPTPN12/miR-21-5 p/Np63alpha pathway contributes to human endometrial fibrosis. eLife 10 e65735

9. Liu E, Lv L, Zhan Y, Ma Y, Feng J, He Y, Wen Y, Zhang Y, Pu Q, Ji F, et al: METTL3/N6-methyladenosine/ miR-21-5p promotes obstructive renal fibrosis by regulating inflammation through SPRY1/ERK/NF- $\kappa$ B pathway activation. J Cell Mol Med 25: 7660-7674, 2021

10. Qiao L, Hu S, Liu S, Zhang H, Ma H, Huang K, Li Z, Su T, Vandergriff A, Tang J, et al: microRNA-21-5p dysregulation in exosomes derived from heart failure patients impairs regenerative potential. J Clin Invest 129: 2237-2250, 2019.

11. Raupach A, Torregroza C, Niestegge J, Feige K, Klemm-Meyer S, Bauer I, Brandenburger T, Grievink H, Heinen A and Huhn R: MiR-21-5p but not miR-1-3p expression is modulated by preconditioning in a rat model of myocardial infarction. Mol Biol Rep 47: 6669-6677, 2020.

12. Dai B, Li H, Fan J, Zhao Y, Yin Z, Nie X, Wang DW and Chen C: MiR-21 protected against diabetic cardiomyopathy induced diastolic dysfunction by targeting gelsolin. Cardiovasc Diabetol 17: 123, 2018.

13. Balcells I, Cirera S and Busk PK: Specific and sensitive quantitative RT-PCR of miRNAs with DNA primers. BMC Biotechnol 11: 70,2011.

14. Livak KJ and Schmittgen TD: Analysis of relative gene expression data using real-time quantitative PCR and the 2(-Delta Delta C(T)) Method. Methods 25: 402-408, 2001.

15. Xia Y, Gong L, Liu H, Luo B, Li B, Li R, Li B, Lv M, Pan J and An F: Inhibition of prolyl hydroxylase 3 ameliorates cardiac dysfunction in diabetic cardiomyopathy. Mol Cell Endocrinol 403: 21-29, 2015.

16. Wang CC and Reusch JE: Diabetes and cardiovascular disease: Changing the focus from glycemic control to improving long-term survival. Am J Cardiol 110 (Suppl 9): 58B-68B, 2012.

17. Lee Y and Gustafsson AB: Role of apoptosis in cardiovascular disease. Apoptosis 14: 536-548, 2009.

18. Shekhar A, Heeger P, Reutelingsperger C, Arbustini E, Narula N Hofstra L, Bax JJ and Narula J: Targeted Imaging for Cell Death in Cardiovascular Disorders. JACC Cardiovasc Imaging 11: 476-493, 2018

19. Song Z, Shen F, Zhang Z, Wu S and Zhu G: Calpain inhibition ameliorates depression-like behaviors by reducing inflammation and promoting synaptic protein expression in the hippocampus. Neuropharmacology 174: 108175, 2020.
20. Song Z, Chen H, Xu W, Wu S and Zhu G: Basolateral amygdala calpain is required for extinction of contextual fear-memory. Neurobiol Learn Mem 155: 180-188, 2018.

21. Myers MP, Stolarov JP, Eng C, Li J, Wang SI, Wigler MH, Parsons R and Tonks NK: P-TEN, the tumor suppressor from human chromosome 10q23, is a dual-specificity phosphatase. Proc Natl Acad Sci USA 94: 9052-9057, 1997.

22. Shi YH, Wang YX, You JF, Heng WJ, Zhong HH and Fang WG Activation of HIF-1 by bFGF in breast cancer: Role of PI-3K and MEK1/ERK pathways. Zhonghua Yi Xue Za Zhi 84: 1899-1903, 2004. (In Chinese)

23. Song ZJ, Yang SJ, Han L, Wang B and Zhu G: Postnatal calpeptin treatment causes hippocampal neurodevelopmental defects in neonatal rats. Neural Regen Res 14: 834-840, 2019.

24. Li D, Qu Y, Mao M, Zhang X, Li J, Ferriero D and Mu D: Involvement of the PTEN-AKT-FOXO3a pathway in neuronal apoptosis in developing rat brain after hypoxia-ischemia. J Cereb Blood Flow Metab 29: 1903-1913, 2009.

25. Landgraf P, Rusu M, Sheridan R, Sewer A, Iovino N, Aravin A, Pfeffer S, Rice A, Kamphorst AO, Landthaler M, et al: A mammalian microRNA expression atlas based on small RNA library sequencing. Cell 129: 1401-1414, 2007.

26. Sayed D, He M, Hong C, Gao S, Rane S, Yang Z and Abdellatif M: MicroRNA-21 is a downstream effector of AKT that mediates its antiapoptotic effects via suppression of Fas ligand. J Biol Chem 285: 20281-20290, 2010.

27. Cheng Y, Liu X, Zhang S, Lin Y, Yang J and Zhang C: MicroRNA-21 protects against the $\mathrm{H}(2) \mathrm{O}(2)$-induced injury on cardiac myocytes via its target gene PDCD4. J Mol Cell Cardiol 47: 5-14, 2009

28. He Z, Long J, Yang C, Gong B, Cheng M, Wang Q and Tang J: LncRNA DGCR5 plays a tumor-suppressive role in glioma via the miR-21/Smad7 and miR-23a/PTEN axes. Aging (Albany NY) 12: 20285-20307, 2020.

29. Wang J, Yue J, Xia Q, Jiao X and Zhi J: Angiotensin II type i receptor agonistic autoantibodies induces apoptosis of cardiomyocytes by downregulating miR21 in preeclampsia: A mechanism study. Am J Transl Res 11: 2339-2349, 2019.

30. Roy S, Khanna S, Hussain SR, Biswas S, Azad A, Rink C, Gnyawali S, Shilo S, Nuovo GJ and Sen CK: MicroRNA expression in response to murine myocardial infarction: miR-21 regulates fibroblast metalloprotease- 2 via phosphatase and tensin homologue. Cardiovase Res 82: 21-29, 2009.

31. Meng F, Henson R, Wehbe-Janek H, Ghoshal K, Jacob ST and Patel T: MicroRNA-21 regulates expression of the PTEN tumor suppressor gene in human hepatocellular cancer. Gastroenterology 133: 647-658, 2007.

32. Shen F, Song Z, Xie P, Li L, Wang B, Peng D and Zhu G: Polygonatum sibiricum polysaccharide prevents depression-like behaviors by reducing oxidative stress, inflammation, and cellular and synaptic damage. J Ethnopharmacol 275: 114164, 2021.

33. Qian M, Tan HM, Yu N, Wang T and Zhang Q: Inactivated Sendai Virus Induces ROS-dependent Apoptosis and Autophagy in Human Prostate Cancer Cells. Biomed Environ Sci 31: 280-289, 2018.

34. Yang H, Xie Y, Yang D and Ren D: Oxidative stress-induced apoptosis in granulosa cells involves JNK, p53 and Puma. Oncotarget 8: 25310-25322, 2017.

35. Sears CE, Ashley EA and Casadei B: Nitric oxide control of cardiac function: Is neuronal nitric oxide synthase a key component? Philos Trans R Soc Lond B Biol Sci 359: 1021-1044, 2004.

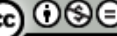

This work is licensed under a Creative Commons Attribution-NonCommercial-NoDerivatives 4.0 International (CC BY-NC-ND 4.0) License. 